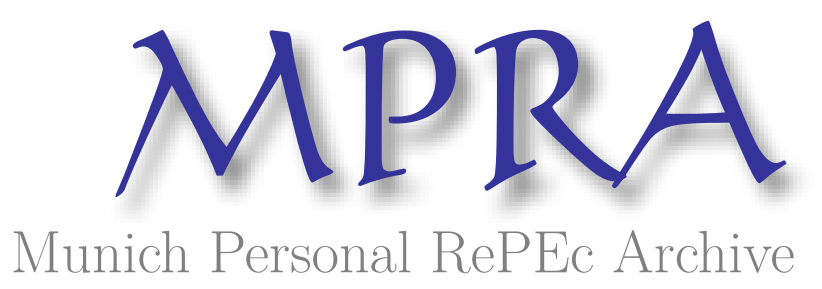

\title{
Withdrawal Rates, Savings Rates, and Valuation-Based Asset Allocation
}

Pfau, Wade Donald

National Graduate Institute for Policy Studies (GRIPS)

10 December 2011

Online at https://mpra.ub.uni-muenchen.de/35329/

MPRA Paper No. 35329, posted 10 Dec 2011 15:20 UTC 


\title{
Withdrawal Rates, Savings Rates, and Valuation-Based Asset Allocation
}

\author{
by \\ Wade D. Pfau \\ Associate Professor \\ National Graduate Institute for Policy Studies (GRIPS) \\ 7-22-1 Roppongi, Minato-ku, Tokyo 106-8677 Japan \\ Email: wpfau@grips.ac.jp \\ phone: 81-3-6439-6225
}

\begin{abstract}
While most everyone would agree that valuations matter, the question remains as to whether clients with a long-term outlook (such as those planning for retirement) can hope to act successfully on information about valuations. This article provides favorable evidence based on the historical record for long-term conservative investors to obtain improved retirement planning outcomes (lower savings rates, higher withdrawal rates) using valuation-based asset allocation strategies. This is illustrated with a specific example comparing a 50/50 fixed allocation strategy to a Graham and Dodd inspired valuation-based strategy with a stock allocation of 25,50 , or $75 \%$ determined by the value of the cyclically-adjusted price-earnings ratio with respect to its median value up to that point in history. Important caveats are discussed. But even if clients or advisors decide against adopting valuation-based asset allocation, advisors may at least be able to use the findings of this research to help persuade clients to stay the course and not give in to the temptation to change their asset allocations in the "wrong direction," such as increasing stock holdings after valuations rise or panicking and selling stocks after a plummet in valuations.
\end{abstract}

JEL Codes: C15, D14, G11, G14, G17, N21, N22

Keywords: market valuations, cyclically-adjusted price-earnings ratio, PE10, stock returns, asset allocation

Acknowledgements: I am grateful for financial support from the Japan Society for the Promotion of Science Grants-in-Aid for Young Scientists (B) \#23730272. 


\section{Introduction}

In an interview from the December 2011 Journal of Financial Planning, Lance Ritchlin asked William Bengen, "What do you see as the next step regarding research into safe withdrawal rates?" Bengen replied, "I think that was something... where you vary, now, the investment approach based on some criteria that have yet to be defined, whether it be value or something else...I think all the research done has pretty much assumed a portfolio with a pretty constant stockbond ratio throughout the whole time of the client's retirement." I will provide an attempt to fulfill Mr. Bengen's research suggestion. I investigate the role of a valuation-based asset allocation strategy for a client's accumulation and retirement phases. Such an approach is not unknown to readers of the $J F P$, as in the same issue, Solow, Kitces, and Locatelli (2011) investigate how these sorts of strategies improve risk-adjusted returns.

Based on previous work described in Campbell and Shiller (1998) and other research papers, Shiller (2000) popularized the notion that valuation ratios, specifically a cyclically-adjusted $\mathrm{P} / \mathrm{E}$ ratio that is price divided by average real earnings over the previous 120 months (PE10), can provide predictive power for long-term real stock market returns. Checking the relationship between PE10 and subsequent 10-year real stock returns with updated data reveals that PE10 explains $30.2 \%$ of the variation in these subsequent returns. The explanatory power increases to as much as $60 \%$ for 19 -year average real stock returns. Because such regressions are estimated using overlapping observations, as the same year data point is used in the construction of both variables over multiple periods, scholars have subsequently debated whether the relationship is statistically significant. Shiller (2000) provides a review of this literature. More generally, economists often worry more about statistical significance than economic significance, and Shiller (2010) understands this point when he writes, "A regression would not indicate a terribly good fit, but it is a good enough fit to suggest that there is something to this model" (page 52).

In seeking to determine the economic significance of this relationship, this research explores whether otherwise passive and conservative long-term investors can exploit it to obtain improved retirement planning outcomes in comparison to a fixed asset allocation strategy with the same average allocation to stocks. Strategic asset allocation involves deciding on an allocation to properly balance risk and return objectives after considering factors such as capital market expectations, age, job stability, existing wealth, planned expenditures, risk tolerance, and other factors affecting the willingness and ability to bear risk. While most everyone would agree that valuations matter, the question remains as to whether clients with long-term horizons can hope to 
act successfully on information about valuations. Should market valuations, through their effect on capital market expectations, be added to the list of characteristics clients consider when determining their asset allocation?

The long-term focus is important. Market valuation levels tend to revert to their mean over long periods of time. When PE10 is low, markets tend to exhibit mean reversion and relatively higher future returns can be expected. But because the precise timing of this mean reversion is not known in advance, and is indeed random, expecting the result to happen in the short-term will not be possible. This research is indeed grounded in the notion that attempting to beat the market in the short run is futile. It can take years for the mean reversion to happen. But can patient clients find a strategy to take advantage of this mean reversion in market valuation levels?

As a case study, I will compare a fixed 50/50 asset allocation strategy against a strategy introduced by Graham and Dodd (1940), in which investors maintain a 50/50 asset allocation when valuations fall within a range between $2 / 3$ and $4 / 3$ of their historical average value; the stock allocation is $75 \%$ when valuations are less than $2 / 3$ of their average and $25 \%$ when valuations are more than $4 / 3$ of their average. These numerical bounds correspond to evolving PE10 values of approximately 10 and 21 over time. I will demonstrate the potential for valuation-based asset allocation strategies to increase the Bengen (1994) style worst-case scenario SAFEMAX withdrawal rate as well as maximum sustainable withdrawal rates in general, to decrease the savings rate needed to meet a wealth accumulation target at retirement, and to decrease the Pfau (2011a) style "safe" savings rate needed to meet one's retirement spending goals without worrying about the implied wealth accumulation or withdrawal rate. Valuation-based strategies have demonstrated historical success.

My claim for historical success will be controversial, at least as to whether I have effectively avoided look-back bias, whether taxes and transaction costs would overturn the results, and whether such success can be expected to continue in the future. Nevertheless, at least for clients inclined to adjust their allocation in response to market valuations, the sorts of mechanical rules outlined here would provide a better alternative than emotion-based and arbitrary market-timing decisions. Generally, investors tend to give in and increase stock allocations near a market peak and then panic and decrease allocations after a market drop. It is the opposite of what should happen. Jenkins (1961) argues that formulas, "most certainly help to protect the investor against the dangers of emotionalism, and offer a guide to action that can protect him from acting under the perhaps unwise impulse of the moment" (page 21). Incorporating valuation-based asset allocation into an 
Investment Policy Statement could provide the psychological resolve to weather big market drops, especially as such drops tend to occur when valuations are high and so the investor would already be at a lower stock allocation. As well, if nothing more, the results from this study could be used to help persuade clients to stay the course rather than move in the wrong direction.

\section{Literature Review}

Jenkins (1961) reviews the history of stock formula investing plans, which obtained great popularity between the 1930s and 1950s. Some of these formula plans are still extremely popular today, such as dollar-cost averaging, buy-and-hold (which implies not rebalancing), and the constant-ratio plan, which today is better known as buy-and-hold with periodic rebalancing either at specific time intervals or when deviations from the targeted asset allocation become sufficiently large. Here, I refer to constant-ratio plans as "fixed allocation."

In this research, I update into modern form a type of formula plan which Jenkins would have included in his chapter on variable-ratio plans. These plans were based on trend-lines, moving averages, and intrinsic values. Their underlying theme was that stock markets tend to exhibit cyclical patterns over time. Stock allocations should increase when stock prices/values are relatively low, and allocations should decrease when prices/values are relatively high. Or, as Lucille Tomlinson (1953) describes, “a Variable Ratio formula provides for smaller percentages of stocks in high market areas, where the risk of owning stocks is greatest, and for larger percentages in low market areas, where the risk of loss is bound to be considerably less" (page 167). More generally, stock formula plans were meant to guide investors with mechanical rules that prevent behavioral mistakes of feeling regret and increasing stock allocations when prices are at their peak, or of panicking and selling stocks when prices are at their trough.

Though earlier writers were investigating asset allocation strategies that real people might consider using, an unfortunate detour in much of the recent research about "market timing" has been to compare only a $100 \%$ stocks fixed allocation strategy against a strategy switching between $100 \%$ stocks and $100 \%$ cash as dictated by the timing rule in which changes are made even when the market is just slightly above or slightly below its "fair valuation level." Studies considering only extreme allocation choices include Smithers and Wright (2000), and Stein and DeMuth (2003), who find supporting evidence for timing, and Fisher and Statman (2006) and Blanchett (2011), who find opposing evidence for timing. 
Focusing on the negative studies, Fisher and Statman (2006) is one of the few extant studies providing counter evidence to the idea that a market-timing strategy guided by existing valuation measures with relatively few trades made over a long period of time can improve risk-adjusted investment returns. However, their investigation is limited by their comparison of the above mentioned extreme strategies. $100 \%$ stocks is a rather volatile benchmark for comparison that is generally not used by conservative household investors. Ex ante, it also has a much higher average stock allocation that the timing strategies. The failure of their extreme market-timing strategies to hedge against the possibility that valuations can deviate from their average levels for extended periods is also an important concern. As for Blanchett (2011), the timing decisions are made randomly, and the Monte Carlo simulation produces returns that are independent over time, leaving no role for valuation feedbacks. This will not be convincing to anyone who believes that valuations may be beneficial in predicting long-term returns.

Responding, in particular, to the Fisher and Statman study, Pfau (2012) finds that most every permutation of valuation-based asset allocation strategies based on PE10 demonstrate strong potential to improve risk-adjusted returns for conservative long-term investors. Such valuationbased strategies provide comparable returns as $100 \%$ stocks, but with substantially less risk according to a wide variety of risk measures. Meanwhile, valuation-based strategies provide comparable risks and the same average asset allocation as a 50/50 fixed allocation strategy, but with much higher returns. When comparing the absolute returns for different strategies, the 50/50 fixed allocation strategy provides a more suitable benchmark, as it allows for comparisons between strategies with similar risk and the same average stock allocation.

Having already implicitly understood the need for more suitable comparison groups and more realistic allocation choices, Solow, Kitces, and Locatelli (2011) is another study arguing that valuation-based strategies can improve risk-adjusted returns. Though they may have overstated the case for statistical significance by not considering that their data observations are overlapping rather than independent, they do provide a compelling case that capital market expectations do differ in a dramatic fashion between high and low valuation environments.

The above studies describe the situation for the accumulation phase. For retirement decumulation, Kitces (2008) and Pfau (2011b) both use fixed asset allocations to explore the relationship between retirement date valuations and sustainable withdrawal rates. Kitces (2008) argues that safe withdrawal rates are higher when valuations are low, and Pfau (2011b) extends this idea with a regression model including dividend yields and bond yields to show that historically a 
close relationship has existed between sustainable withdrawal rates and these variables, suggesting that we can obtain fairly reasonable predictions for the sustainable withdrawal rate based on conditions at the retirement date. Kitces (2009) also investigates the impacts of valuation-based strategies on sustainable withdrawal rates, arguing that incorporating valuations into asset allocation decisions can help increase the safe withdrawal rate.

\section{Methodology and Data}

I use a historical simulations approach, considering the perspective of clients retiring in each year of the historical period. An individual saves for retirement during the final 30 years of her career, and she earns a constant real income in each of these years. A fixed savings rate determines the fraction of this income she saves at the end of each of the 30 years. Retirement begins at the start of the $31^{\text {st }}$ year, and the retirement period is assumed to last for 30 years. The accumulation and decumulation lifecycle is 60 years. Withdrawals are made at the beginning of each year during retirement. Withdrawal amounts are defined as a replacement rate from final pre-retirement salary and are adjusted for inflation in subsequent years. I assume that the client wishes to replace $100 \%$ of her final salary with withdrawals from her accumulated wealth. Since this does not account for Social Security, other income sources, or the fact that savings reduce pre-retirement expenditures, this replacement rate is surely too high for most everyone. But the savings rates resulting from this assumption can be multiplied by a fraction for other replacement rates (multiply the savings rate by 0.75 for a $75 \%$ replacement rate, for instance).

Investment portfolios include large-capitalization stocks (Standard and Poor Composite Stock Price Index) and short-term fixed income assets (annual yield from 6-month commercial paper rates). The investment portfolio is rebalanced to the targeted asset allocation at the start of each year. With these 139 years of data, I consider 30-year careers which are followed by retirements beginning in the years 1901 to 2010. As well, I consider 30-year retirements beginning between 1871 and 1980. To consider a 60-year lifecycle with 30 years of work followed by 30 years of retirement, there are 80 overlapping periods with retirements beginning between 1901 and 1980 .

Robert Shiller's website (http://www.econ.yale.edu/ shiller/data.htm) provides the data. The PE10 measure is the stock price in January divided by the average real earnings on a monthly basis over the previous 10 years. Campbell and Shiller (1998) justify this measure as a way to remove cyclical factors from earnings. The concept derives from Graham and Dodd (1940), who said "the period for averaging earnings would ordinarily be seven to ten years" (page 686). PE10 
has become a widely accepted valuation measure despite lacking a precise theoretical underpinning for the choice of 10 years, and so I use it to avoid look-back bias in case another definition provides even stronger results. Solow, Kitces, and Locatelli (2011) suggest instead using five years of earnings.

There are infinite ways for creating a formula plan, with various choices being made about how to change asset allocations and which valuation indicators to use for decision rules. Look-back bias is a real problem, as it could be easy to keep searching for a formula plan that works with the historical data but would not necessarily have been chosen in advance. There are three ways to try to limit such bias: choose a formula plan created long ago, decide on the formula parameters in advance before looking at the data, and check for robustness by confirming the results for many different plan variations. Though more frequent action is possible, I only consider clients who check whether a revision for their asset allocation is required at the beginning of each year.

I will illustrate this concept with one valuation-based strategy. Having looked at many permutations, some aspects of this strategy (such as using the rolling historical median to define fair value PE10) were chosen specifically because they result in the worst wealth accumulations for the valuations strategy. The strategy I will illustrate is representative of what can be expected and is not chosen because it provides a misleadingly positive portrait. Pfau (2012) shows results for many other strategies during long accumulation periods. The strategy considered here is inspired by Graham and Dodd (1940). They suggest that a neutral 50/50 strategic allocation be maintained as long as PE10 falls within a band between $2 / 3$ and $4 / 3$ of its historical average. I define the historical average as the rolling median between the start date and that point in history. This is a plausible choice, and ex-post it also performs relatively poorly, providing a further check against look-back bias. More extreme allocations are used only when PE10 moves outside these bounds, with a 25\% stock allocation when PE10 is high and a 75\% stock allocation when PE10 is low. Asset allocation changes can be made by directing new contributions and by rebalancing.

Figure 1 shows PE10 along with the bounds for the Graham and Dodd decision rules, as well as the corresponding asset allocation for each year in the historical record. Between 1871 and 1914, both strategies shared the same allocation in every year except 1899 (PE10 cannot be calculated until 1881 since 10 years of data are needed, so I assume the valuation-based strategy uses 50/50 for 1871-1880). This explains why the outcomes will be quite similar during the early part of the historical period. Between 1915 and 1944, the asset allocation does change rather frequently. For 1944 through 1961, both strategies share the same allocation. For 6 years in the 
1960s, the valuation-based strategy uses a lower stock allocation, and from the mid-1970s to mid1980s, the tendency is toward a higher stock allocation. From 1985 through 1992, the allocations were again the same, and then as the market boomed in the 1990s the valuations strategy uses a lower stock allocation for all years between 1993 and 2008, except for 1995. Over the historical period, there were 28 allocation changes, for an average of one change every 5 years.

Figure 1

PE10 Historical Data with Graham and Dodd Asset Allocation Decision Rule

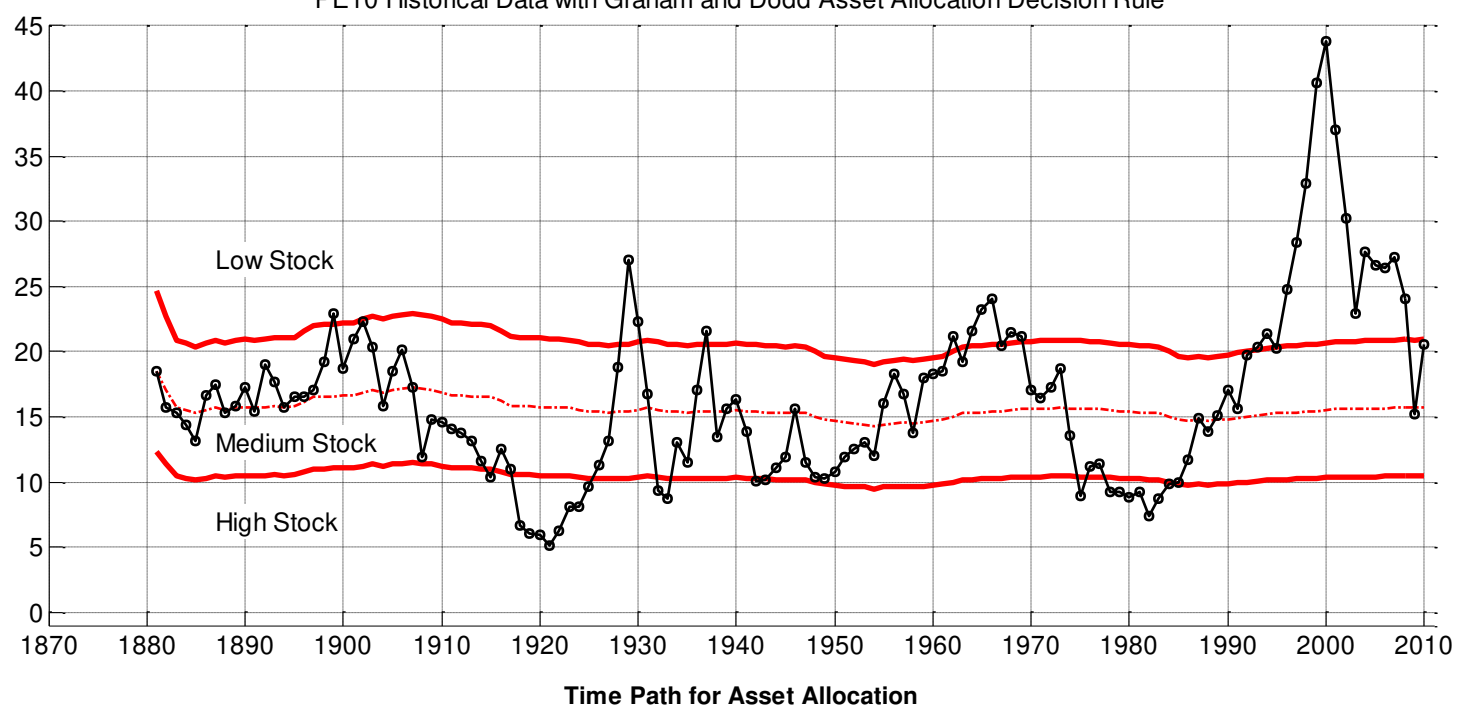

Time Path for Asset Allocation

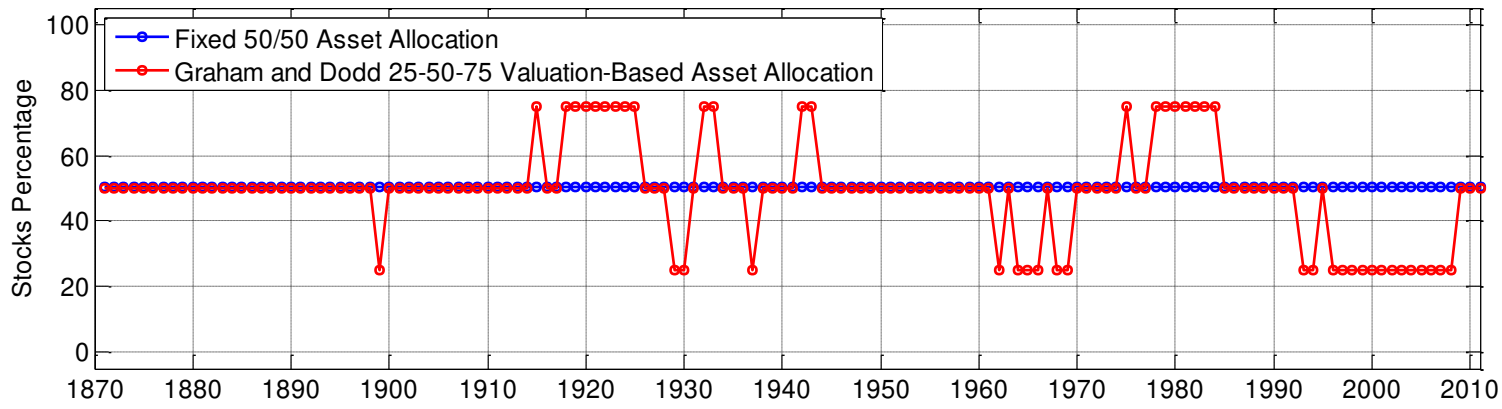

\section{Valuation-Based Asset Allocation and Maximum Sustainable Withdrawal Rates}

Figure 2 shows the historical maximum sustainable withdrawal rates (MWRs) for 30 years of inflation-adjusted withdrawals with a fixed 50/50 and a Graham and Dodd 25-50-75 valuationbased asset allocation. MWRs vary among studies due to differences in datasets, asset allocations, fees, when withdrawals are made, and other matters. In Figure 2, the SAFEMAX worst-case withdrawal rate occurred for both strategies in 1937. With a fixed 50/50 strategy, the SAFEMAX was $3.93 \%$. With the valuation-based strategy, the SAFEMAX was $4.58 \%$. If the SAFEMAX is the 
criterion used to define a "safe withdrawal rate," then the valuation-based strategy would offer conservative retirees the opportunity to raise their portfolio spending by nearly $17 \%$. Another low point occurred for 1966 retirees, when the 50/50 fixed strategy supported a 4.14\% withdrawal rate, compared to $4.6 \%$ for the valuation-based strategy. More generally, the valuation-based strategy supports as high or higher withdrawal rates over 30-year retirements across the historical period, with differences of over 2 percentage points in a few years. The years 1979 and 1980 provide the only exceptions, as by then, the underperformance of the valuation-based strategy during the prolonged market boom with soaring valuations in the 1990s begins to show its effect. Nevertheless, the underperformance of the valuation-based strategies in those two years is not critical, as both strategies supported relatively high withdrawal rates of over $7 \%$.

Figure 2

Maximum Sustainable Withdrawal Rates (MWR)

For Fixed and Valuation-Based Asset Allocation, 30-Year Retirement Period
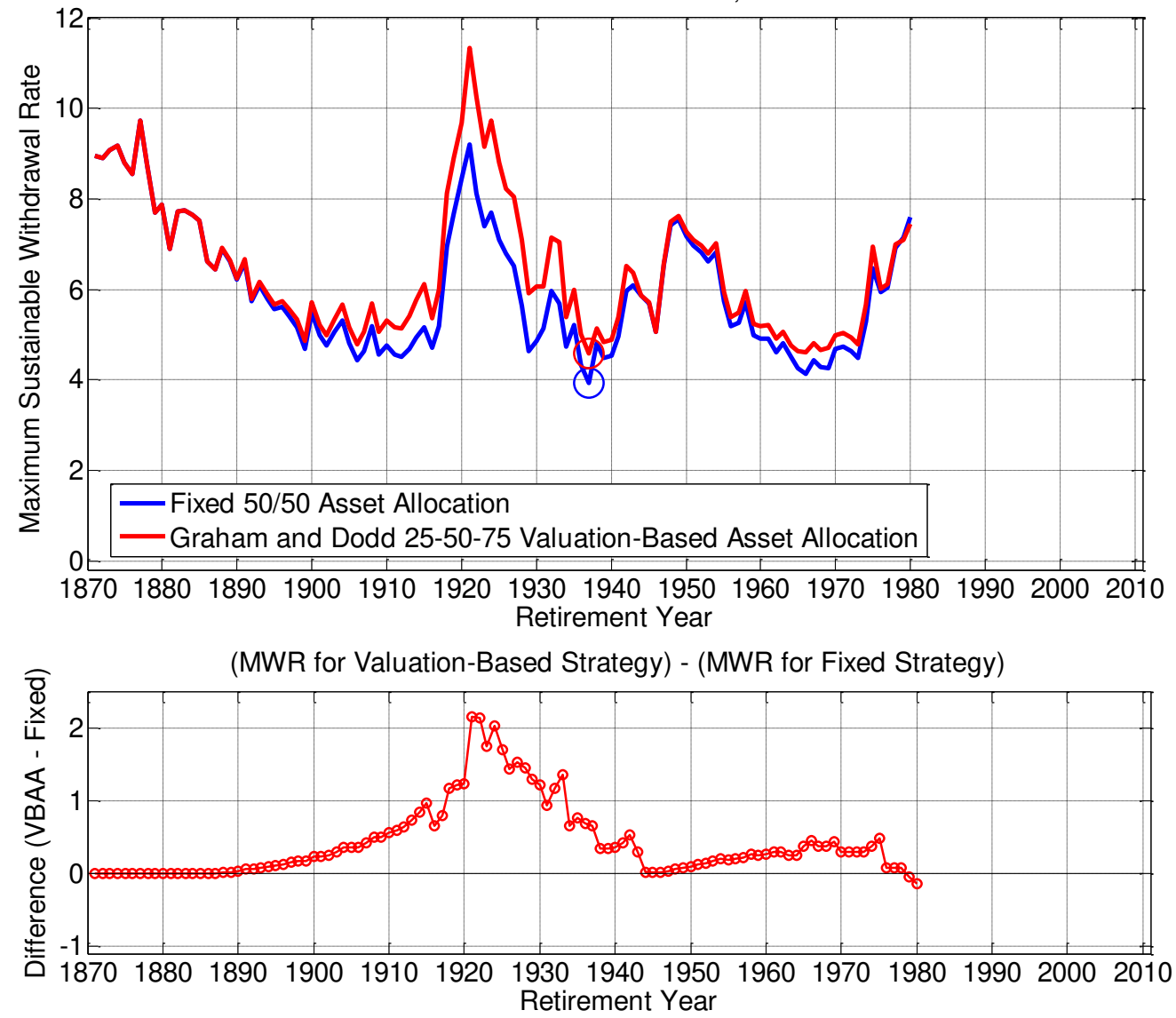


\section{Valuation-Based Asset Allocation and Savings Rates to Meet a Wealth Accumulation Target}

Figure 3

Minimum Savings Rate Needed to Reach 25x Wealth Accumulation Target (MSR) For Fixed and Valuation-Based Asset Allocation, 30-Year Work Period
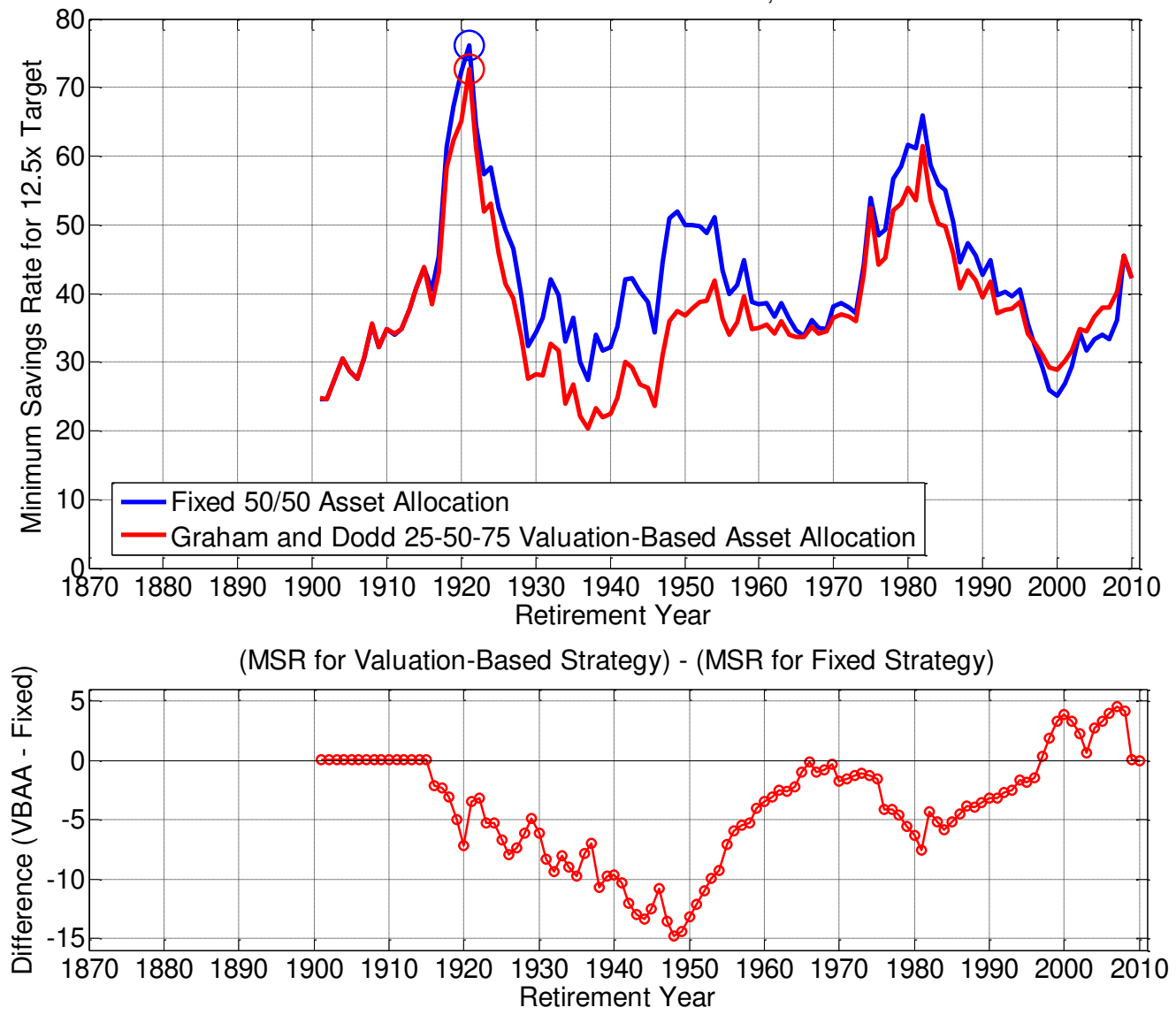

Next, consider the savings rate (MSR) needed over a 30-year career to achieve a wealth accumulation target of 25 multiples of salary by retirement. This would be the amount needed for traditional retirement planning to use a "safe" $4 \%$ withdrawal rate to replace $100 \%$ of a client's preretirement income. Again, for practical purposes, this replacement rate is too high, but planners can multiply the savings rates by the appropriate fraction to obtain the savings rate for any desired replacement rate. The valuation-based asset allocation strategy can bring the client to their wealth accumulation target with a lower savings rate than the corresponding fixed allocation strategy. The SAFEMIN savings rate, which would be the lowest savings rate required in the worst-case scenario, happened for both strategies in 1921. For the valuation-based strategy, the savings rate was $72.7 \%$, which is 3.5 percentage points less than the $76.2 \%$ for the fixed allocation strategy. In some years, 
the valuation-based strategy supported a lower annual savings rate by as much as 15 percentage points. The exception is that for the years 1997 through 2009, the fixed allocation strategy allowed for a lower savings rate. This results, again, from the massive stock market boom in the late 1990s which led valuations to unprecedented highs while the valuation-based investor maintained a lower stock allocation. The underperformance in these cases is the price for insurance against the more likely outcome of lower stock returns when valuations are high. For the fixed allocation strategy, the lowest possible savings rate of $25.1 \%$ can be found for new retirees in 2000 , while the valuation-based strategy allowed 1937 retirees to meet their wealth accumulation target with a savings rate of $20.4 \%$.

\section{Valuation-Based Asset Allocation and "Safe" Savings Rates}

Figure 4

"Safe" Savings Rates for Fixed and Valuation-Based Asset Allocation For 30-Year Work Period, 30-Year Retirement Period, 100\% Replacement Rate
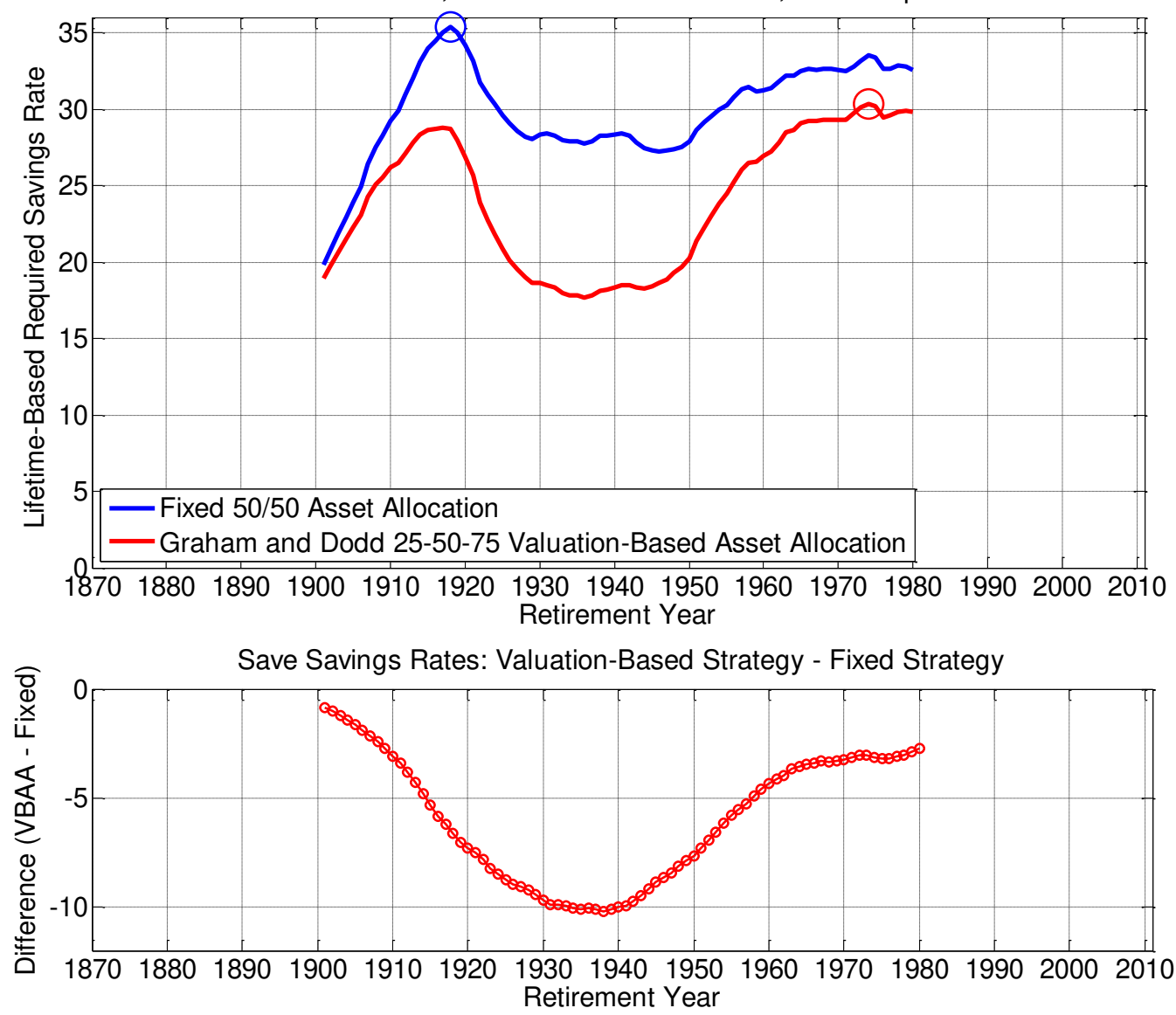
As Pfau (2011a) notes, there is a close correspondence between the MWRs and MSRs for each retirement year. Years when retirees were fortunate to meet their wealth goal with a relatively low savings rate tended to find that their retirement period supported a low withdrawal rate. Meanwhile, those unfortunate to retire in years when the required savings rate was quite high, also tended to find that the withdrawal rate they could have used was relatively high as well. Pfau (2011a) suggests, for this reason, to integrate the working and retirement phases to determine the savings rate needed to finance the planned retirement expenditures for rolling 60-year periods from the data, without concern for the implied wealth accumulation and withdrawal rate at the retirement date. That is the "safe" savings rate. Comparing the two strategies, the valuation-based strategy offers a lower savings rate at every point in history. The highest of these was $30.4 \%$ in 1974 for the valuation-based strategy, and $35.4 \%$ in 1918 for the fixed allocation strategy.

\section{Conclusions}

This article provides favorable evidence based on the historical record for long-term conservative investors to obtain improved retirement planning outcomes (lower savings rates, higher withdrawal rates) using valuation-based asset allocation strategies. This is illustrated with a specific example comparing a 50/50 fixed allocation strategy to the Graham and Dodd valuationbased strategy with a stock allocation of 25,50 , or $75 \%$ determined by the value of PE10 with respect to its rolling median value. There are a number of caveats though, such as the problem that index funds did not exist until the 1970s making it quite costly to implement either of these strategies in the past, and taxes or transactions costs have not been incorporated. Implementing the valuation-based allocation strategy does require a certain disposition, as it is a contrarian strategy requiring lower stock allocations when people are most giddy about stocks, and requiring higher stock allocations when panic has set in for the typical investor. The fact that the strategies "worked" historically also does not guarantee future success.

Nonetheless, this research does propose a potential asset allocation approach for advisors and clients wishing to incorporate valuations into their asset allocation choices, but also wishing to maintain a formal commitment to an asset allocation decision framework that will hopefully help prevent hasty emotion-based decisions. Even if clients or advisors decide against adopting valuation-based asset allocation, I hope that advisors may at least be able to use the results of this research to help persuade clients to stay the course and not give in to the temptation to change their asset allocations in the "wrong direction" as stock prices and valuations fluctuate. 


\section{References}

Bengen, William P. 1994. "Determining Withdrawal Rates Using Historical Data." Journal of Financial Planning 7, 4 (October): 171-180.

Blanchett, David. 2011. "Is Buy and Hold Dead? Exploring the Costs of Tactical Reallocation." Journal of Financial Planning 24, 2 (February): 54-61.

Campbell, John Y., and Robert J. Shiller. 1998. "Valuation Ratios and the Long-Run Stock Market Outlook." Journal of Portfolio Management 24, 2 (Winter): 11-26.

Fisher, Kenneth L., and Meir Statman. 2006. "Market Timing in Regression and Reality." Journal of Financial Research 29, 3 (Fall): 293-304.

Graham, Benjamin, and David Dodd. 1940. Security Analysis (The Classic 1940 Second Edition). New York: McGraw-Hill.

Jenkins, David. 1961. How to Profit From Formula Plans in the Stock Market. Larchmont, NY: American Research Council.

Kitces, Michael E. 2008. "Resolving the Paradox - Is the Safe Withdrawal Rate Sometimes Too Safe?" The Kitces Report (May).

Kitces, Michael E. 2009. "Dynamic Asset Allocation and Safe Withdrawal Rates" The Kitces Report (April).

Pfau, Wade D. 2011a. "Safe Savings Rates: A New Approach to Retirement Planning over the Life Cycle." Journal of Financial Planning 24, 5 (May): 42-50.

Pfau, Wade D. 2011b. "Can We Predict the Sustainable Withdrawal Rate for New Retirees?" Journal of Financial Planning 24, 8 (August): 40-47.

Pfau, Wade D. 2012. "Long-Term Investors and Valuation-Based Asset Allocation." Applied Financial Economics, forthcoming.

Ritchlin, Lance. 2011. "William Bengen on Risk, Volatility, and Safe Withdrawal Rates in Today's Markets." Journal of Financial Planning 24, 12 (December): 18-20.

Shiller, Robert J. 2000. Irrational Exhuberance. $2^{\text {nd }}$ Edition. New York: Currency Doubleday.

Shiller, Robert J. 2010. "Irrational Exuberance Revisited." Behavioral Finance and Investment Management. Edited by Arnold S. Wood. Charlottesville: Research Foundation of the CFA Institute.

Smithers, Andrew, and Stephen Wright. 2000. Valuing Wall Street: Protecting Wealth in Turbulent Markets. New York: McGraw-Hill.

Solow, Kenneth, R., Michael E. Kitces, and Sauro Locatelli. 2011. "Improving Risk-Adjusted Returns using Market-Valuation-Based Tactical Asset Allocation Strategies." Journal of Financial Planning 24, 12 (Deember): 38-49.

Stein, Ben, and Phil DeMuth. 2003. Yes, You Can Time the Market. Hoboken: John Wiley and Sons. Tomlinson, Lucille. 1953. Practical Formulas for Successful Investing. New York: Wilfred Funk. 